\title{
PENINGKATAN KINERJA KOPERASI MERTANADI MENDUKUNG USAHATANI ASPARAGUS BERKELANJUTAN DI DESA PELAGA, KABUPATEN BADUNG
}

\author{
I N Gede Ustriyana1 ${ }^{1}$ I G A A Lies Anggreni ${ }^{2}$, I M Sarjana ${ }^{3}$
}

\begin{abstract}
ABSTRAK
Kegiatan pengabdian kepada masyarakat ini bertujuan untuk meningkatkan kinerja usaha koperasi tani Mertanadi dalam mendukung usahatani asparagus secara berkelanjutan di Desa Pelaga, Kabupaten Badung.Usahatani asparagus merupakan program OVOP (one village one product) yang mulai dikembangkan sejak tahun 2010, sebagai salah satu upaya peningkatan pendapatan masyarakat. Metode yang digunakan dalam melaksanakan kegiatan tersebut agar lebih efektif dalam mencapai tujuan adalah Metode yang digunakan dalam kegiatan pemberdayaan masyarakat ini, diantaranya : (1) Penyuluhan, (2) Pelatihan, dan (3) Pendampingan. Pendekatan yang digunakan, yaitu: (1) model partisipatory ruralappraisal (PRA), (2) model entrepreneurship capacity building (ECB), (3) model teknologi transfer (TT) dan (4) model informasi teknologi (IT).Hasil yang diperoleh menunjukkan bahwa kegiatan pengabdian kepada masyarakat di Desa Pelaga, Kecamatan Petang, Kabupaten Badung, dapat berlangsung dengan baik, adanya partisipasi aktif masyarakat dan adopsi iptek yang tinggi. Partisipasi aktif mitra pada seluruh kegiatan cukup tinggi.
\end{abstract}

Kata kunci:ovop, koperasi tani, asparagus

\begin{abstract}
Community service activity is aimed to improve the performance of Mertanadi farm cooperatives in supporting sustainable asparagus farming in Desa Pelaga, Badung regency. Asparagus farming is an OVOP (one village one product) program which was developed since 2010, as an effort to increase people's income. The methods used in carrying out these activities to be more effective in achieving the objectives are the methods used in this community empowerment activities, including: (1) Counseling, (2) Training, and (3) Assistance. The approach used is: (1) participatory rural appraisal (PRA) model, (2) entrepreneurship capacity building model (ECB), (3) technology transfer model (TT) and (4) information technology model (IT). The results show that community service activities in Pelaga Village, Petang Sub-district, Badung Regency, can take place well, the active participation of the community and the adoption of high science and technology. Active participation of partners on all activities is quite high.
\end{abstract}

Keywords: ovop, farm cooperatives, asparagus

\section{PENDAHULUAN}

Desa Pelaga Kecamatan Petang Kabupaten Badung merupakan satu-satunya lokasi pengembangan asparagus di Provinsi Bali sejak tahun 2010. Adanya asparagus di Desa Pelaga diawali oleh program dari Kementrian Koperasi dan UKM melalui program

1,2,3 Dosen Program Studi Agribisnis Fakultas Pertanian Universitas Udayana 
OneVillage One Product(OVOP). Pemerintah Kabupaten Badung (Dinas Koperasi Perindustrian dan Perdagangan Kabupaten Badung) bekerja sama dengan konsultan dari Taiwan International Cooperation Development Fund (ICDF) mencoba dalam bentuk pilot project seluas 0,5 hektar.

Kondisi agroklimat dilihat dari segi iklim, curah hujan, suhu udara dan topografi daerah Pelaga Kecamatan Petang sudah cocok dengan syarat tumbuh tanaman asparagus sehingga usahatani ini dapat dikembangkan. Kendala yang dihadapi petani dalam pengembangan usahatani asparagus dari aspek teknis yaitu masalah hama dan penyakit yang menyerang di musim hujan, kurangnya pelatihan pembuatan bibit untuk petani asparagus, dari aspek ekonomi yaitu kekurangan biaya untuk proses produksi, tidak adanya pemasaran untuk hasil produksi yang tidak memenuhi standar grade.

\section{METODE PEMECAHAN MASALAH}

\subsection{Metode}

Metode yang digunakan dalam melaksanakan kegiatan tersebut agar lebih efektif dalam mencapai tujuan adalah Metode yang digunakan dalam kegiatan pemberdayaan masyarakat ini, diantaranya : (1) Penyuluhan, (2) Pelatihan, dan (3) Pendampingan. Pendekatan yang digunakan, yaitu: (1) model partisipatory ruralappraisal (PRA), (2) model entrepreneurship capacity building (ECB), (3) model teknologi transfer (TT) dan (4) model informasi teknologi (IT).

\subsection{Tahapan kegiatan}

Kegiatan pengabdian ini dilaksanakan dalam tiga tahap meliputi tahap persiapan, pelaksanaan, dan pelaporan. Pada persiapan, tim pelaksana kegiatan melakukan kunjungan pendahuluan guna menginventarisasi permasalahan yang dihadapi pengurus koperasi dan anggotanya. Dalam kunjungan ini, tim berdialog dengan beberapa petani anggota kelompok tani, juga pengurus koperasi.

Hasil observasi secara ada tiga permasalahan krusial yang dihadapi Koperasi Tani Mertanadi yakni aspek budidaya asparagus dan hortikultura lainnya, penanganan pasca panen, serta profesionalisme pengelolaan koperasi. Oleh karena itu, kegiatan pengabdian kepada masyarakat ini dibagi menjadi tiga meliputi: (1) Konsultasi budidaya dan penanganan hama penyakit asparagus dan hrotikultura lainnya, (2) Konsultasi penangan pasca panen dan pengolahan asparagus jadi produk lain, (3) pendampingan penyusunan Standar Operating Procedure (SOP) manajemen koperasi 


\section{HASIL DAN PEMBAHASAN}

Kegiatan ini dibuka pada Rabu, 29 Nopember 2017 dan dilaksanakan secara intensif antara Bulan Nopember dan Desember 2017. Secara rinci pelaksanaan masing-masing kegiatan dipaparkan sebagai berikut.

\subsection{Konsultasi Budidaya Asparagus dan Hortikultura lainnya}

Tim konsultasi teknik budidaya terdiri dari Prof. Dr. Ir. I Made Sudana, MS.,Dr. Khamdan Khalimi, SP, MP dan Ir. IGN Raka, MS memaparkan teknik-teknik budidaya pertanian organik terutama pengendalian hama dan penyakitnya. Kegiatan ini direspon secara antusia oleh sekitar 70 petani anggota koperasi yang hadir. Berdasarkan data yang diperoleh dari pengurus Koperasi Mertanadi secara keseluruhan petani anggota koperasi tersebut 134 petani, namun yang aktif menyalurkan produknya kekoperasi hanya 80 petani. Artinya, antusiasme petani dalam mengikuti kegiatan ini sangat tinggi.

\subsection{Konsultasi Pascapanen dan Pengolahan Asparagus}

Ir. Agus Selamet Duniaji dari PS. Ilmu dan Teknologi Pangan, Fakultas Teknologi Pertanian Universitas Udayana dan Ir. IGA Lies Angraini, M.Par dari Prodi Agribisnis FP Unud menjadi nara sumber pada konsultasi pascapanen dan pengolahan asparagus. Dua narasumber tersebut menjelaskan ke petani upaya penanganan pasca panen asparagus dilakukan dengan dua cara yakni: 1) Pasca panen (postharvest)/ pengolahan primer (primary processing). perlakuan dari mulai panen sampai komoditas dapat dikonsumsi "segar" atau untuk persiapan pengolahan berikutnya. Umumnya perlakuan tersebut tidak mengubah bentuk penampilan, kedalamnya termasuk berbagai aspek dari pemasaran dan distribusi. 2) Pengolahan (processing)/ secondary processing yaknitindakan yang mengubah hasil tanaman ke kondisi atau bentuk lain, tujuannya dapat tahan lebih lama (pengawetan) atau mencegah perubahan yang tidak dikehendaki.

\subsection{Pendampingan Penyusunan SOP Pengelolaan Koperasi.}

Dr. I. I Nyoman Gede Ustriyana, MM bersama I Made Sarjana, SP.M.Sc bertindak selaku nara sumber dan pendamping penyusunan peraturan khusus atau standar operating procedure (SOP) manajemen koperasi (Gambar 4.4). Dijelaskan, penyusunan SOP Koperasi Tani Mertanadi dimaksudkan sebagaiperaturan yang memuat ketentuan-ketentuan dan prosedur tentang pengelolaan Koperasi, sebagai panduan dan pedoman bagi Pengurus, Pengawas, Pengelola, Karyawan maupun Anggota. SOP ini disusun atas dasar Visi, Misi dan Tujuan 
dibentuknya Koperasi sebagai Badan Usaha mengacu pada Undang - Undang No. 25 Tahun 1992 dan AD / ART Koperasi Tani Mertanadi.

Adapun SOP harus mengacu pada visi dan misi koperasi bersangkutan.Visi Koperasi Tani Mertanadi adalah terwujudnya lembaga jasa/pelayanan yang mampu mengelola pelayanan usaha agribisnis asparagus dan hortikultura lainnyaa secara professional berdasarkan pada nilai - nilai dan prinsip - prinsip koperasi. Sementara itu misi yang ingin direalisasikan adalah sebagai berikut:

1. Mengembangkan sikap saling menolong di antara para anggota, calon anggota dan masyarakat pada umumnya.

2. Memberikan pelayanan aspek budidaya, pasca panen dan pemasaran asparagus dan hortikultura lainnya secara profesional berdasarkan pada prinsip - prinsip dan manajemen koperasi guna menigkatkan kesejahteraan anggota pada khususnya dan masyarakat pada umumnya.

3. Memperkokoh struktur organisasi kelembagaan koperasi baik internal maupun eksternal.

4. Meningkatkan kualitas Sumber Daya Manusia (SDM) koperasi melalui penyuluhan, pendidikan dan pelatihan.

5. Menjalin kerja sama dalam Gerakan Koperasi Tani secara horisontal maupun vertikal dengan lembaga-lembaga mitra, baik pemerintah maupun non pemerintah.

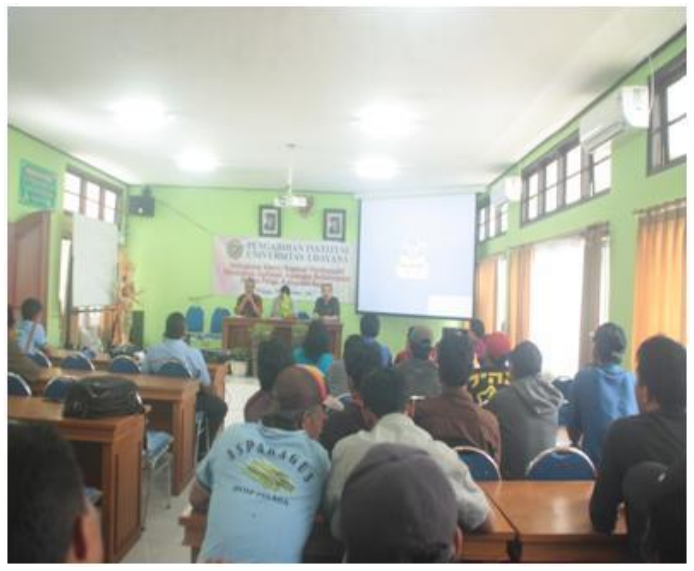

Gambar 3.1 Suasana Pembukaan Pengabdian Masyarakat di Koperasi Tani Mertanadi

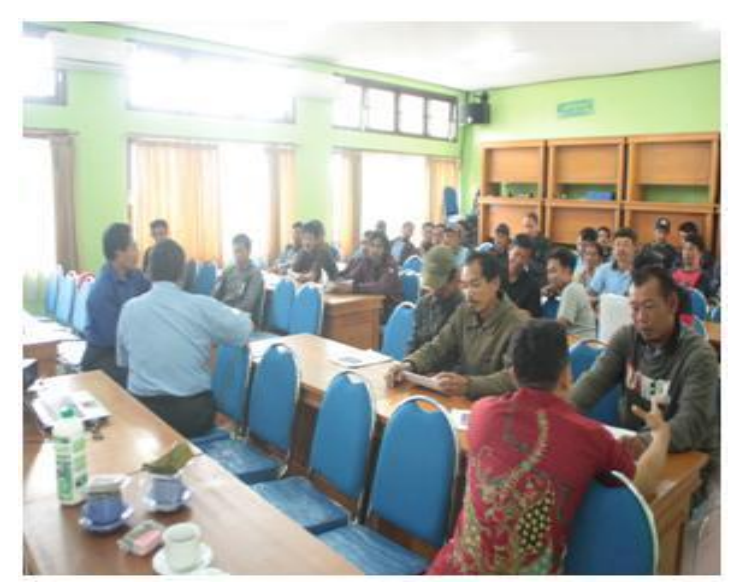

Gambar 3.2 Kegiatan Konsultasi Budidaya Asparagus dan Hortikultura lainnya. 


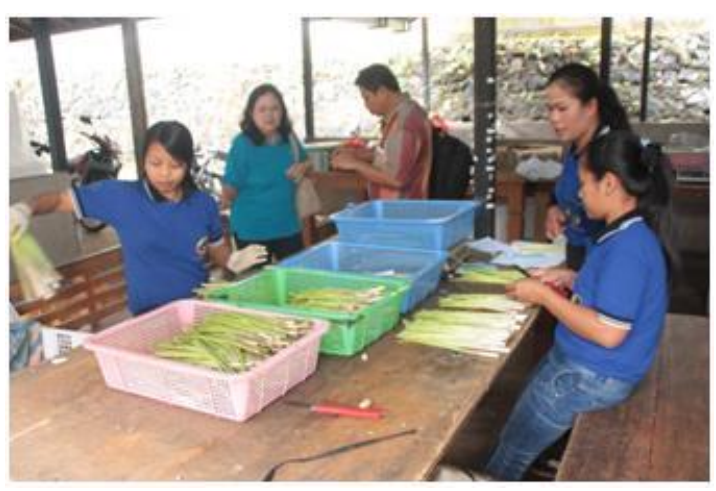

Gambar 3.3 Konsultasi Penanganan Pasca Panen dan Pengolahan

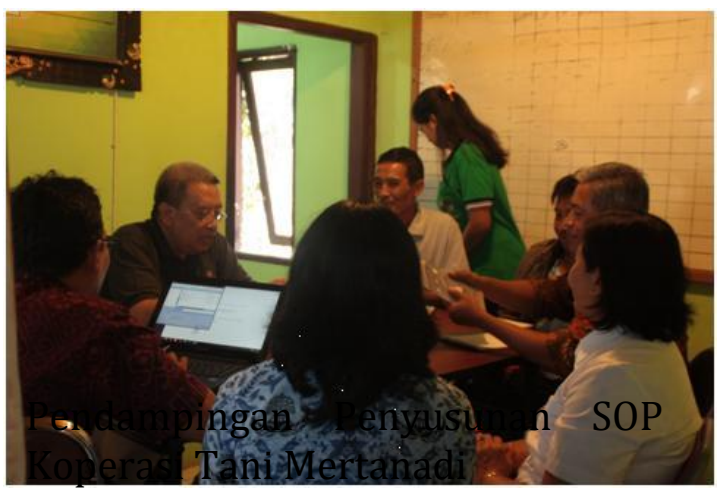

Gambar 3.5 Pendampingan Penyusunan SOP Koperasi Tani Mertanadi

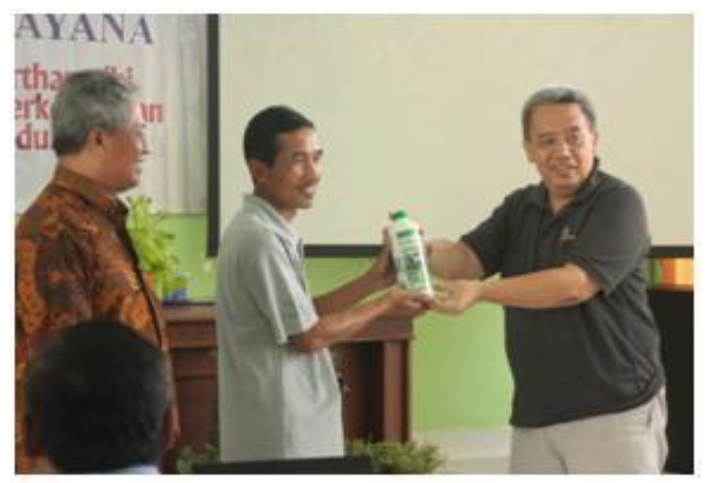

Gambar 3.4 Penyerahan Bantuan Pupuk Cair Nabati bagi Petani Asparagus.

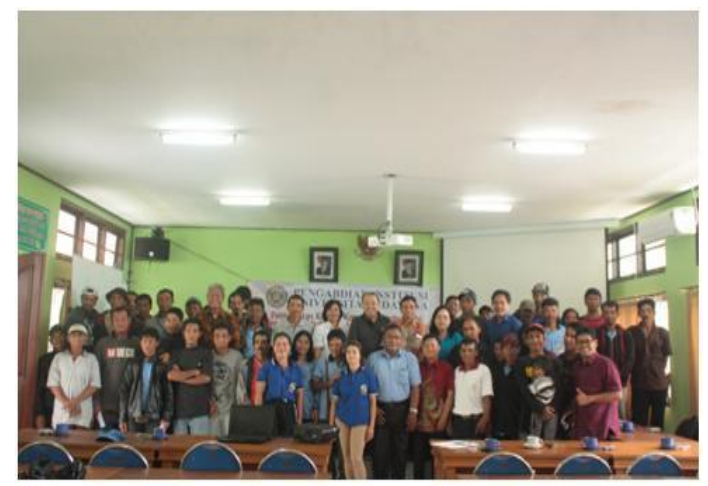

Gambar 3.6 Foto Bersama antara instruktur dan khalayak sasaran pengabdian masyarakat.

\section{KESIMPULAN DAN SARAN}

\subsection{Kesimpulan}

Mencermati uraian sebelumnya maka ditarik sejumlah kesimpulan sebagai berikut:

1. Petani Asparagus selaku anggota Koperasi Tani Mertanadi memiliki pengetahuan dan ketrampilan mengelola usaha tani asparagus dan hortikultura lainnya, memiliki pengetahuan yang terbatas dalam aspek budidaya, dan penanganan hama dan penyakit tanaman asparagus. Konsultasi budidaya dan penanganan hama dan penyakit asparagus menjadi solusi tepat mengatasi masalah tersebut. Terbukti, petani sangat antusias mengikuti kegiatan tersebut, dari 80 petani yang diundang, 70 orang diantaranya hadir untuk mengikuti kegiatan tersebut.

2. Pegawai koperasi yang menangani pasca panen dan pengolahan hasil panen asparagus dan hortikultura lainnya, sudah memiliki ketrampilan yang memadai. Hanya saja, wawasan dan ketrampilannya mesti disegarkan secara terus menerus sehingga produktivitasnya dalam menghasilkan kemasan dan produk lainnya dengan kualitas yang sesuai dengan 
ekspektasi pasar harus terus diupayakan. Konsultasi penanganan pasca panen dan pengolahan ini menjadi satu bentuk penyegaran wawasan tersebut.

3. Pengurus Koperasi Tani Mertanadi belum memiliki peraturan khusus atau SOP yang memadai dalam menjalankan roda organisasi koperasi. Kegiatan pendampingan penyusunan SOP menjadi solusi jitu menghasilkan SOP yang sesuai kebutuhan koperasi tersebut. SOP hasil pengabdian masyarakat ini akan dibahas di Rapat Anggota Tahun (RAT) untuk disahkan selanjutnya dijadikan pedoman dalam mengelola koperasi tersebut.

\subsection{Saran}

Adapun saran yang dapat diajukan setelah pelaksanaan pengabdian masyarakat ini adalah sebagai berikut:

1. Kebersamaan petani bergabung sebagai anggota Koperasi Tani Mertanadi sudah berjalan baik, dan koperasi juga sudah menjalankan fungsinya dengan baik yakni memfasilitasi berbagai kebutuhan petani selaku anggota mulai dari penyediaan sarana produks pertanian, pelatihan, pemasaran produk dan lain-lain. Kepercayaan antara anggota dan lembaga harus terus ditingkatkan sehingga kebersamaan harus terus terjalin dengan baik, kinerja koperasi meningkat, dan pendapatan petani juga meningkat seiring peningkatan ketrampilan dalam bidang budidaya komoditas pertanian yang memiliki nilai ekonomis tinggi seperti asparagus.

2. Tenaga kerja trampil bidang pertanian tidak tersedia secara langsung dipasaran, maka pelatihan dan pendampingan untuk alih teknologi dalam penangan pasca panen dan pengolahan hasil harus dilakukan secara bertahap dan terus menerus.

3. Peningkatan kinerja pengurus dalam mengelola koperasi memerlukan dukungan regulasi seperti AD/RT dan SOP. Penyusunan SOP menjadi sangat penting dilakukan oleh pengurus dan hal ini patut didukung oleh semua pihak.

\section{UCAPAN TERIMAKASIH}

Penulis menyampaikan terimakasih yang sebesar-besarnya kepada Rektor Universitas Udayana yang telah memberikan bantuan dana melalui Surat Perjanjian Penugasan Pelaksanaan Hibah Pengabdian Institusi LPPM Universitas Udayana Nomor : 1111b9/UN14.4.4.A/PM/2017, tanggal 6 September 2017. Ucapan terima kasih juga disampaikan kepada Pengurus dan seluruh anggota koperasi tani Mertanadi serta Dinas Koperasi kabupaten yang telah membantu kelancaran kegiatan ini. 


\section{DAFTAR PUSTAKA}

Pratiwi, K.R.I, Pascarani, N.N.D., Winaya, I.K. 2016. Evaluasi Pelaksanaan Program One Village One Product (OVOP) dalam Pemberdayaan Masyarakat di Desa Pelaga, Kecamatan Petang, Kabupaten Badung.https://ojs.unud.ac.id/index.php/citizen/article/view/23401

Rahayu, N.W.N. 2015. Aspek Kelayakan Finansial Pengembangan Komoditas Asparagus (Asparagus officionalis) di Desa Pelaga Kecamatan Petang Kabupaten Badung. Sekripsi. Konsentrasi Pengembangan Bisnis Program Studi Agribisnis, Fakultas Pertanian Universitas Udayana, Denpasar

Umbara, I.G.L., 2017. Paparan Perbekel Pelaga Penilaian Lomba Evaluasi Perkembangan Desa 2017. http://pelagaku.badungkab.go.id/wp-content/uploads/2017/08/pemaparan.pdf 